\title{
One-Dimensional Simulation Using Port Water Injection for a Spark Ignition Engine
}

\author{
C. H. Ling ${ }^{1,2}$ and M. A. Abas ${ }^{1,2 *}$ \\ ${ }^{1}$ School of Mechanical Engineering, Faculty of Engineering, \\ Universiti Teknologi Malaysia, 81310 Skudai, Johor, Malaysia \\ *Email: azman.abas@utm.my \\ Phone: +60198789306 \\ ${ }^{2}$ UTM Centre for Low Carbon Transport, Universiti Teknologi Malaysia, \\ 81310 Skudai, Johor, Malaysia
}

\begin{abstract}
Water injection is a promising solution to reduce fuel consumption while improving the performance of a turbocharged gasoline engine. One-dimensional (1D) engine simulation software, AVL BOOST is rarely used to model water injection. Therefore, this study is aimed to demonstrate the detailed port water injection modelling via AVL BOOST. A four-cylinder turbocharged gasoline engine was developed in AVL BOOST based on the specification of the engine test rig and verified to be used as the baseline model. The port water injection modelling was then added to the baseline model. Water to fuel mass ratios of $0.05,0.10,0.15,0.2$ and 0.25 were chosen as the variables to investigate the effect of water injection on the engine performance. The results showed that maximum engine torque and IMEP increased by $10.80 \%$ and $8.65 \%$, respectively at $3000 \mathrm{rpm}$. The water injection also reduced the in-cylinder pressure at the end of the compression stroke, reducing the compression work and improving efficiency. The reduction of combustion temperature also indicates potential for NOx reduction. The lower exhaust temperature can reduce the use of fuel enrichment which consequently reduces the fuel consumption. Conclusively, the water injection model can predict the engine performance parameters accurately.
\end{abstract}

Keywords: AVL BOOST; one-dimensional; port water injection; spark ignition engine

\section{INTRODUCTION}

Water injection (WI) technique has been studied and proposed in recent years since it was applied onto a production car in 2015 [1,2]. There are two general strategic locations to inject the water in spark ignition (SI) engine, namely pre-combustion WI and direct WI. Pre-combustion WI means injecting the water before it enters the combustion chamber and participates in the combustion event. It can be located right before the intake ports, before and after the intercooler or in the intake manifold. On the other hand, direct WI is injecting the water directly to the piston head and post-combustion is injecting the water anywhere after the combustion event completes.

Since the mandate of emission reduction in Europe, the engine downsizing has been the engine design trend in the past decades. This has boosted up the usage of the turbocharger to obtain the same performance out of smaller displacement engines. The turbocharger is good to provide an enormous amount of performance out of a small capacity engine, but the compressed air during the intake stroke means the brake mean 
effective pressure (BMEP) is increased, so reduction of compression ratio is required [3]. The spark timing also needs to be retarded to prevent auto-ignition. Both solutions severely deteriorate the engine efficiency. The fuel economy will decline during high load speed because the fuel enrichment is required to control the turbine inlet temperature (TIT) so that the temperature is in its permissible temperature of the turbine vanes [4].

The main purpose of WI is to mitigate the engine knock by its cooling effect [57]. The latent heat of vaporisation of injected water can absorb the heat which can reduce the knock tendency. Hence, the compression ratio and spark advance can be increased to compensate the efficiency loss of a turbocharged SI engine. Besides, WI can reduce the combustion temperature which controls the TIT. Therefore, the usage of fuel enrichment can be reduced, contributing to better brake specific fuel consumption (BSFC). Since the combustion temperature is reduced, the NOx emission will be reduced as well because its production heavily relies on the combustion temperature [8].

Based on the literature, many prior studies have been reported on the experimental work [7-11]. Iacobacci et al. [9] reported that $20 \%$ of water to fuel mass fraction increases the indicated mean effective pressure (IMEP) up to $7.3 \%$ at $3500 \mathrm{rpm}$. Tornatore et al. [7] concluded that 0.2 water to gasoline mass fraction could reduce up to $12 \%$ of the indicated specific fuel consumption (ISFC) when the engine operates at stoichiometric condition and optimal spark advances. Worm et al. $[10,11]$ stated that the port WI allows up to $35 \%$ increase in full load thermal efficiency with stoichiometric combustion. Mingrui et al. [8] reported that the $15 \%$ direct WI reduces the NO emission by $34.6 \%$ on average. The author also claimed that $15 \%$ of water to fuel ratio provides the optimum advantage in terms of engine performance and emissions.

There are some simulation works that are worth to be highlighted [3, 4, 7, 12-15]. Since this paper is related to numerical approach, only the prior studies which used numerical approach is highlighted. Berni et al. [12] performed the three-dimensional Computational Fluid Dynamic (CFD) simulation on the WI port in a gasoline direct injection (GDI) engine and concluded that the spark advance can be increased due to the lower chemical reactivity of diluted end gases. Breda et al. [3] also utilised the CFD simulation to study the effect of different injection content, namely pure methanol, pure water and $25 \%, 50 \%$, and $75 \%$ of methanol to water, to the spark ignition engine. Wei et al. [15] assessed the direct WI via CFD simulation and the author injected the water at the compression stroke and expansion stroke separately. Wei et al. found that the WI in both compression and expansion stroke exhibits the potential of higher power output from the increase of in-cylinder pressure by about $7 \%$.

GT-Power is the mainstream 1D engine simulation software. Based on the literature, almost all 1D simulation works are accomplished by GT-Power. Bozza et al. [4] used GT-Power to find out the effect of both cooled EGR and intake port WI on the knock resistance and fuel consumption of the SI engine. Bozza et al. [13] performed 1D study through Worldwide Harmonised Light Vehicle Test Procedure (WLTP) and Cycle (WLTC) based on their previous experimental study [7] which proved that intake port WI is a promising technique to increase spark advance and enhance the performance of an SI engine. GT-Power was used to develop the engine model.

On top of the reviews, WI in spark ignition engines studies are still scarce. Most of the available WI research used experimental approach and those using numerical approach is severely lacking. Most of the 1D simulation studies uses GT-Power and the details of modelling are rarely shown. AVL BOOST is also a well-known commercial 1D simulation software, but its application on WI is rather singular. Besides, the WI simulation is not as straightforward as the normal engine simulation because it involves 
multiple species other than fuel. Therefore, this paper aims to focus on the methodology of port WI modelling on a SI engine and validate the simulation results with previous works.

\section{METHODOLOGY}

AVL BOOST $^{\mathrm{TM}}$ v2017.1 was used as the 1D simulation software throughout this study. AVL BOOST is a 1D engine simulation software which can simulate a wide variety of engine, from four-stroke to two-stroke and from spark ignition (SI) to compression ignition (CI). It can basically solve any engine configuration that we can think of. The solver provides optimised simulation algorithms for all available engine elements, such as air filter, turbocharger, injectors, charge air cooler, cylinders and intake manifold. The elements added to the engine model are connected by pipes where the flow in the pipes is treated as 1D. This implies that temperature, pressure, mass flow and wall temperature of all the pipes that are calculated is the mean value across the cross-section of the pipes [16].

\section{Development and Validation of Baseline Model}

The baseline model was first developed based on a 1.6-liter port fuel injection (PFI) turbocharged four-cylinder gasoline engine. The main engine parameters are presented in table 1. The combustion is modeled using Single Vibe function:

$\mathrm{dx} / \mathrm{d} \alpha=\mathrm{a} / \Delta \alpha_{\mathrm{c}} \cdot(\mathrm{m}+1) \cdot \mathrm{y}^{\mathrm{m}} \cdot \mathrm{e}^{-\alpha \cdot \mathrm{y}^{(\mathrm{m}+1)}}$

where $\alpha$ is crank angle, $\mathrm{a}$ is Vibe parameter, $\mathrm{m}$ is shape parameter, $\Delta \alpha_{c}$ is combustion duration. The Vibe function is the simplest approach to model the combustion process. The rate of heat release was specified directly via the start of combustion, combustion duration and the shape parameters. The heat transfer of the engine was calculated via Woschni 1978 model as in Eq. (2).

Table 1. Engine parameters

\begin{tabular}{lc}
\hline Parameters & Specifications \\
\hline Bore & $76 \mathrm{~mm}$ \\
Stroke & $86 \mathrm{~mm}$ \\
Connecting rod length & $130 \mathrm{~mm}$ \\
Compression ratio & $9.5: 1$ \\
Number of valves per cylinder & 4 \\
Intake valve diameter & $21.5^{\circ}$ \\
Intake cam duration & 220-degree CA \\
Intake cam lift & $7.51 \mathrm{~mm}$ \\
Intake valves opening & 357 -degree \\
Intake valves closing & 578 -degree \\
Exhaust cam duration & 224-degree CA \\
Exhaust cam lift & 7.92 mm \\
Exhaust valves opening & 140 -degree \\
Exhaust valves closing & 364-degree \\
\hline
\end{tabular}


$\alpha_{\mathrm{w}}=130 \cdot \mathrm{D}^{-0.2} \cdot \mathrm{p}_{\mathrm{c}}^{0.8} \cdot \mathrm{T}_{\mathrm{c}}^{-0.53} \cdot\left[\mathrm{C}_{1} \cdot \mathrm{c}_{\mathrm{m}}+\mathrm{C}_{2} \cdot \frac{\mathrm{v}_{\mathrm{D}} \cdot \mathrm{T}_{\mathrm{c}, 1}}{\mathrm{p}_{\mathrm{c}, 1} \cdot \mathrm{V}_{\mathrm{c}, 1}} \cdot\left(\mathrm{p}_{\mathrm{c}}-\mathrm{p}_{\mathrm{c}, \mathrm{o}}\right]^{0.8}\right.$

where the surface area and wall temperature of both pistons and cylinder head were defined.

The verified turbocharger map was used as the operating points of the turbocharger element. The Patton, Nitscheke and Heywood model was used to calculate the engine friction based on the defined valve train, cam follower, oil type and the number of camshaft bearings [16]. The model was then tuned to match the experimental results for verification, with the relative error within $5 \%$. The WI system was then configured to simulate the port WI.

\section{Modelling of the Port WI System}

To simulate the injection of water or different types of species, the general species transport was selected in the simulation control menu. The classic transport is the default programme setting. The general species transport allows the solver to calculate based on the thermodynamic properties of the fuel species, such as lower heating value and stoichiometric air-fuel ratio. In short, only a single fuel species is available in classic species transport while the fuel can consist of an arbitrary number of species unless it is specified locally in the injector element which is needed in this study.

In the species set, the composition of the gas was defined as gasoline, $\mathrm{N}_{2}, \mathrm{O}_{2}, \mathrm{CO}_{2}$, $\mathrm{H}_{2} \mathrm{O}$, $\mathrm{CO}$ and $\mathrm{H}_{2}$, minimum seven species as required by BOOST. The mass fraction of the fuel was described under fuel species set table as illustrated in Figure 1. This affects the species setting at the injectors to differentiate the fuel injectors and water injectors.

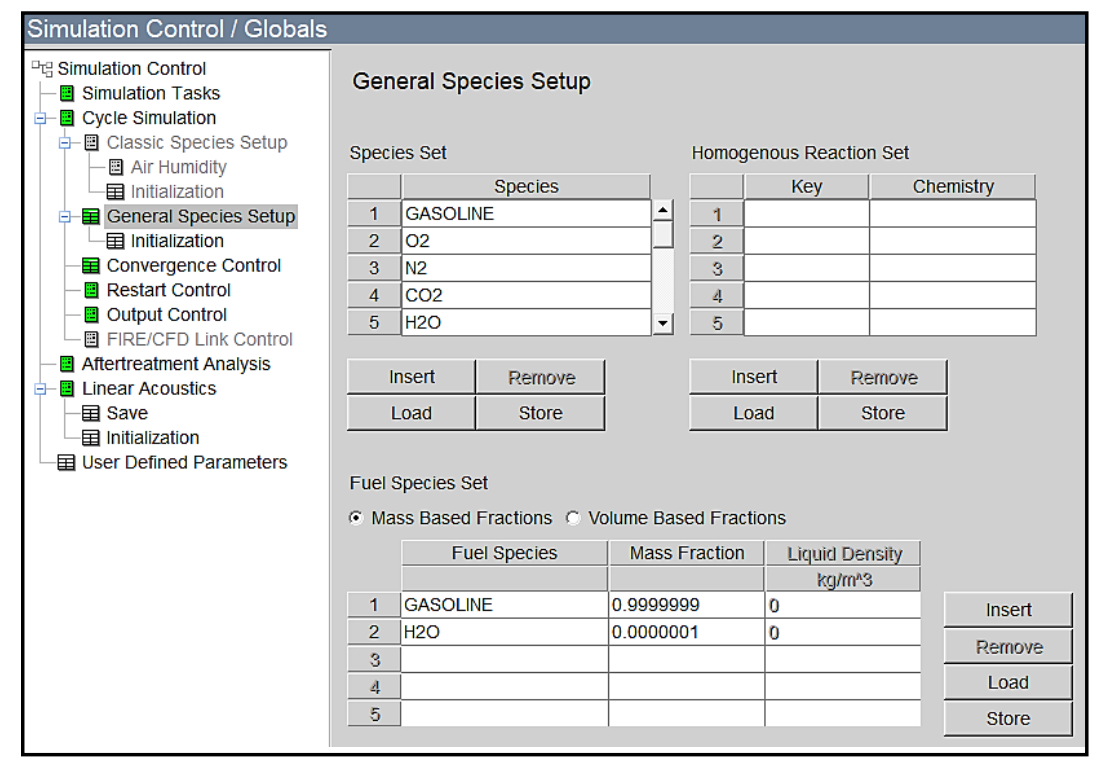

Figure 1. Simulation control window in AVL BOOST.

In the AVL BOOST model, the definition of fuel composition affects the calculation of injector and cylinder in terms of injection and evaporation. Therefore, additional steps and setting modifications were required in both injectors and cylinders so that the water is the species that was injected instead of gasoline. The in-cylinder 
vaporisation of water was considered so that the latent heat of vaporisation of the injected water can play its crucial role as anti-detonation agent.

Additional injector elements were added before the intake valves of each cylinder to perform port WI, other than the injector for gasoline fuel as shown in Figure $2 . I_{1}, I_{2}$, $\mathrm{I}_{3}$, and $\mathrm{I}_{4}$ are fuel injector while $\mathrm{I}_{5}, \mathrm{I}_{6}, \mathrm{I}_{7}$, and $\mathrm{I}_{8}$ are water injectors. Firstly, the continuous injection method was selected instead of intermittent injection. The intermittent injection can simulate a precise crank angle of the start or end of injection, but it requires fuel film formation and evaporation specification as well as distillation curve of the water which were rather complicated. There are no verified data on those parameters as well.

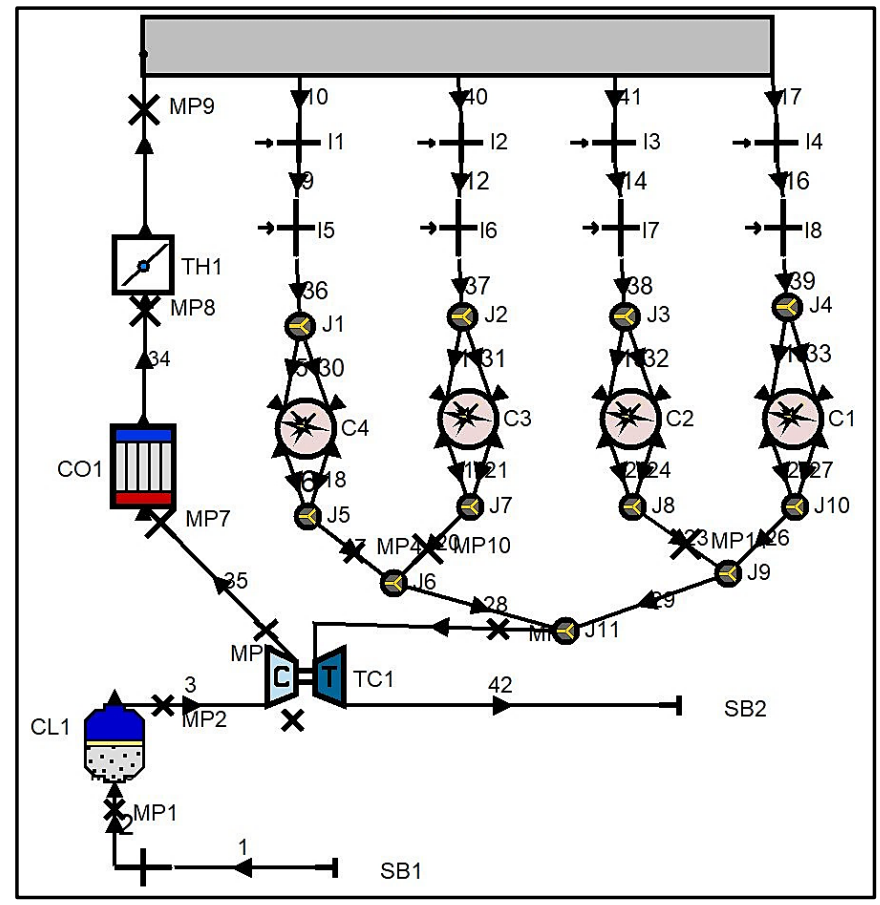

Figure 2. Engine model with port water injectors.

Then, direct control was used to define the mass flow of the injected water. In this study, the mass flow of the injected water was calculated based on the amount of injected fuel as shown in Figure 3(a). Five different water-to-fuel ratios, 5\%, 10\%, 15\%, 20\% and $25 \%$ of water to fuel mass ratio were studied as they were used and concluded to produce positive effect toward the engine performance in a few prior studies. The water temperature was set to $298 \mathrm{~K}$. The heat of evaporation of water was considered in the calculation, so it is defined as $2260 \mathrm{~kJ} / \mathrm{kg}$. Water was set as the local species definition for water injectors as seen in Figure 3(b). In contrary, the fuel was selected as the species to be injected in the fuel injectors.

For the cylinder, the parameters such as the start of combustion and combustion duration under Single Vibe model remained unchanged with WI. In fact, the parameters under other combustion models do not require modification. The in-cylinder evaporation was considered and the heat of evaporation of water was provided to the solver as stated in Figure 4. Under the in-cylinder evaporation setting, the evaporation curve represented the crank angle needed to take all the required heat from the cylinder to evaporate the water and fuel. The crank angle was defined before the combustion starts as shown in Figure 5. The injected liquid water was assumed to completely evaporate before the 
expansion stroke. The engine was operating at wide open throttle (WOT) condition over the range of engine speed from $1000 \mathrm{rpm}$ to $5000 \mathrm{rpm}$.

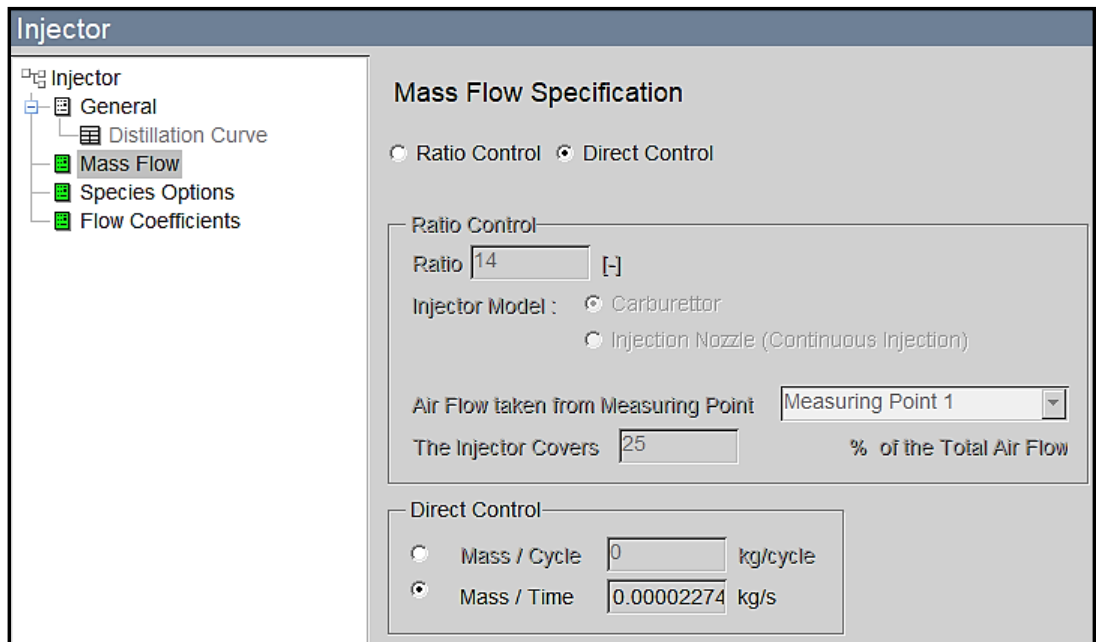

(a)

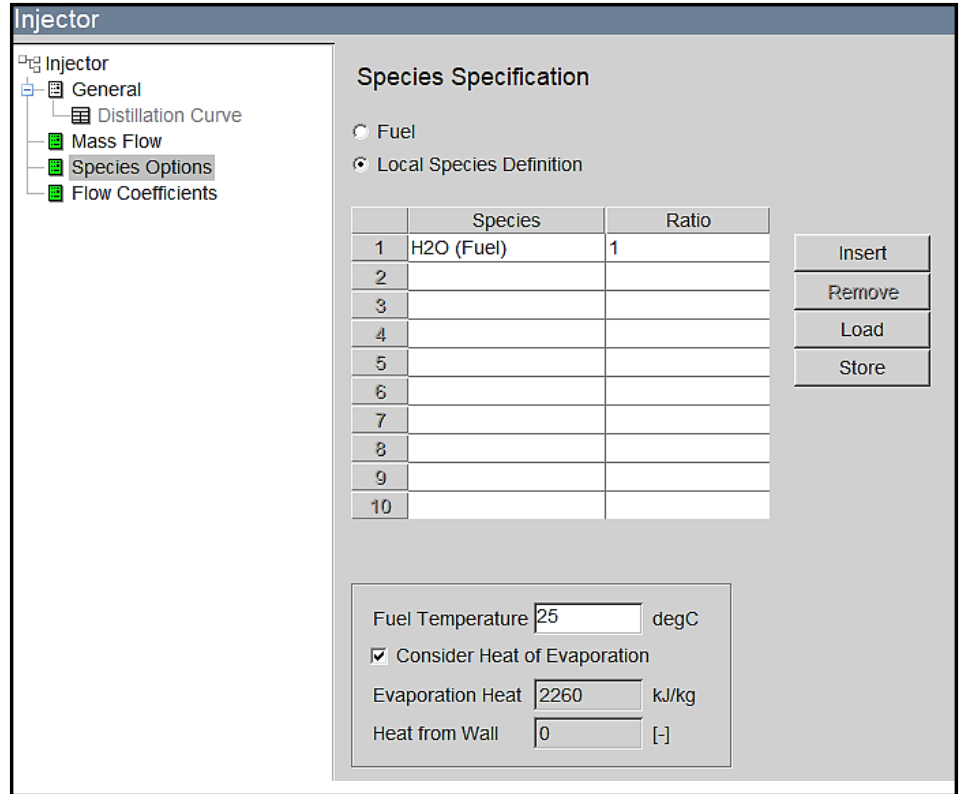

(b)

Figure 3. Setting of (a) the mass flow of the injected fluid and; (b) injected species properties. 


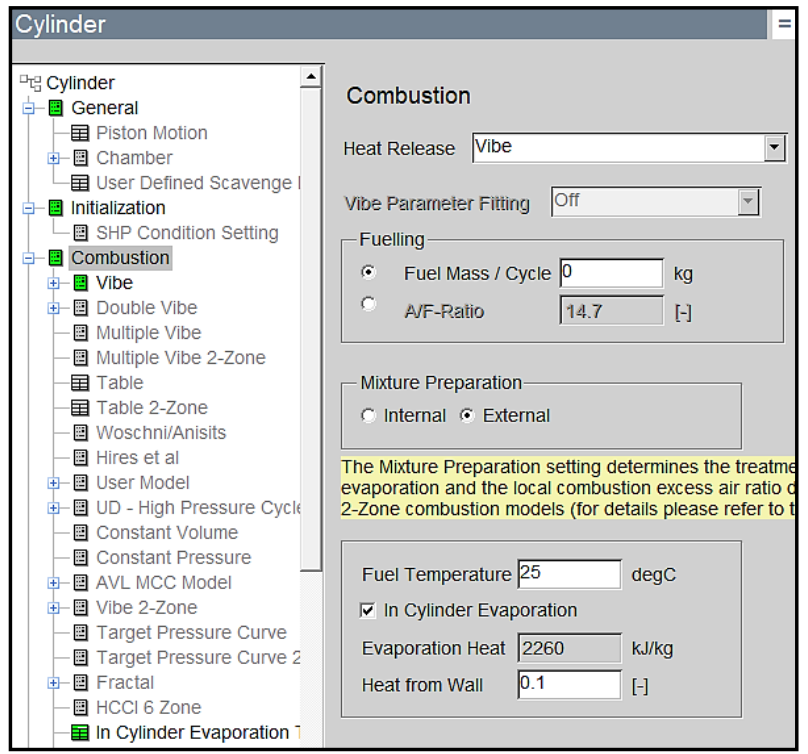

Figure 4. Considering the in-cylinder evaporation in the calculation.

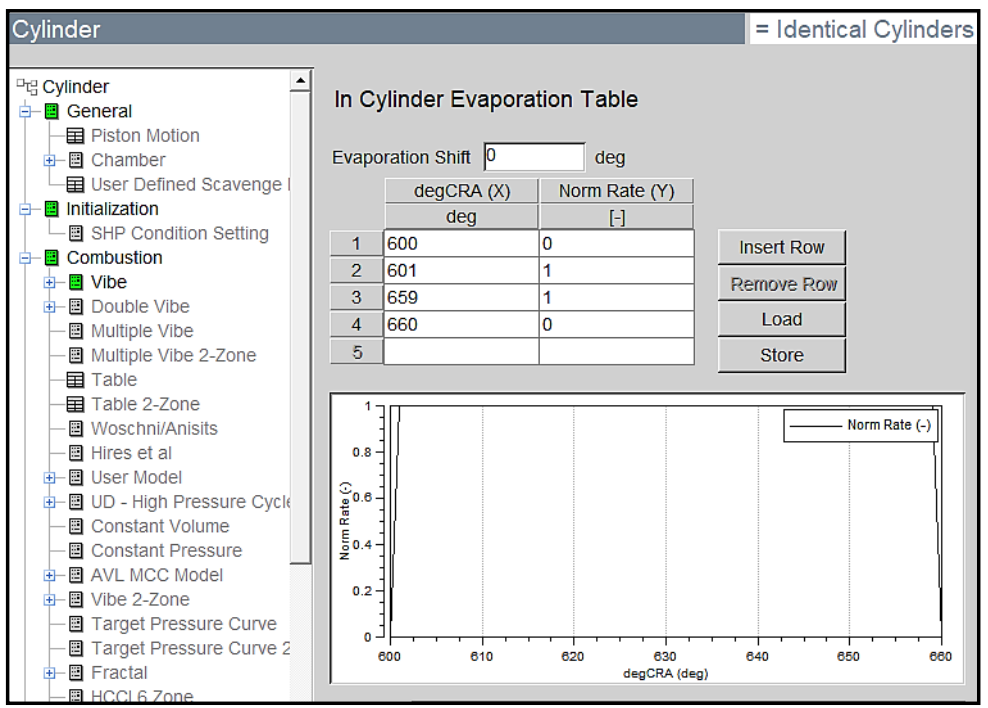

Figure 5. Defining the in-cylinder evaporation table.

\section{RESULTS AND DISCUSSION}

\section{Effect of Port WI on The Combustion Temperature and In-Cylinder Pressure During Compression Stroke}

This paragraph illustrates the effect of WI on the in-cylinder pressure and temperature. Figure 6(a) displays the in-cylinder pressure toward the end of the compression stroke. In general, the plot clearly shows that the in-cylinder pressure reduces toward the end of the compression stroke with WI. This is most probably caused by the temperature reduction by the evaporation of water during the compression stroke as referred in Figure 5, the incylinder evaporation is set to occur at the latter stage of compression stroke. 
However, if observed closely, the in-cylinder pressure reduction is lesser as the amount of the injected water increases which is due to the increase of density of the compressed air. The difference between different water ratio is rather insignificant. Hence, the use of WI reduces the compression work which can improve the engine efficiency. This is because less energy is required to compress the charge air. This advantage should be significant in high compression ratio engine due to the increase of in-cylinder pressure at the latter stage of compression stroke [15]. Besides the reduction of compression work, the reduced pressure also helps to reduce the suction gas losses result from blow-by past the piston rings [14].

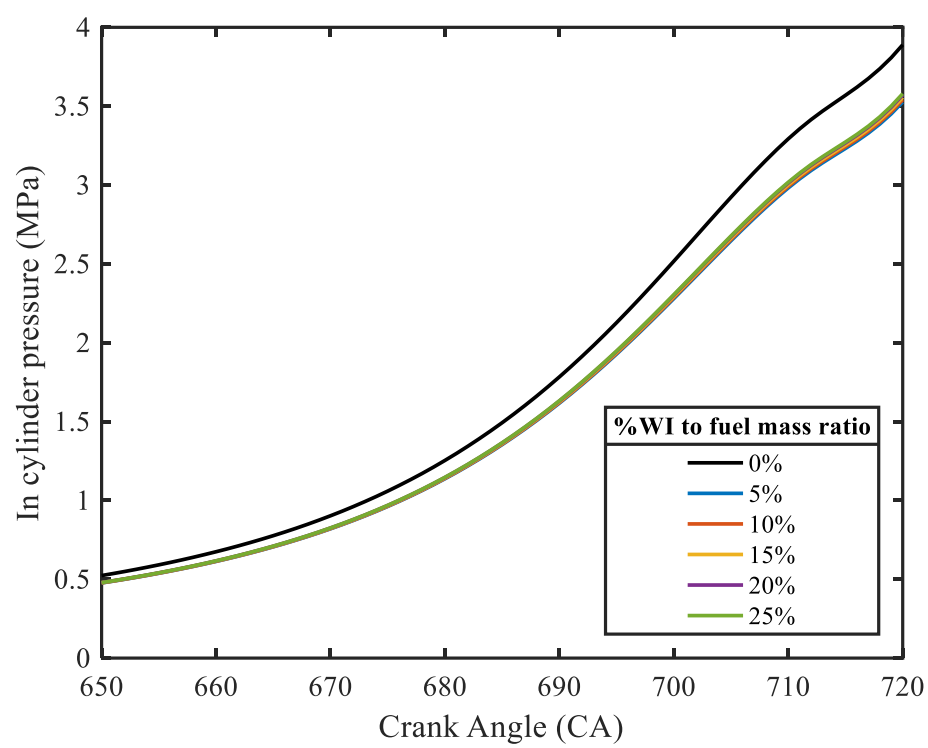

(a)

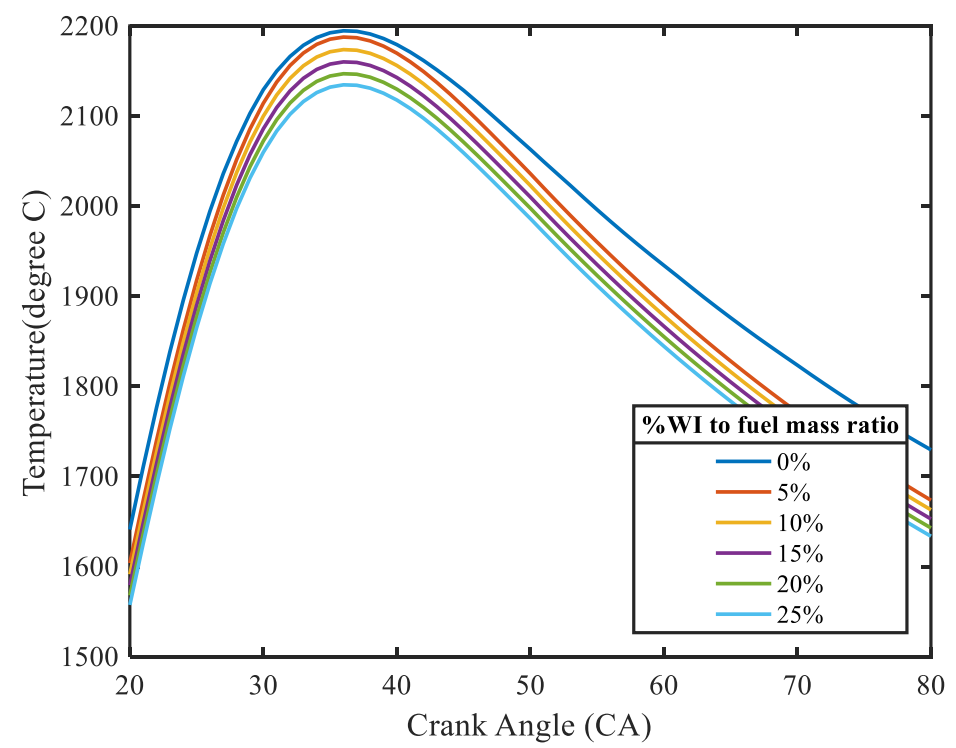

(b)

Figure 6. (a) Peak in-cylinder pressure and; (b) peak in-cylinder temperature responding to crank angle for various cases of WI percentage to fuel mass ratio. 
Figure 6(b) illustrates the peak temperature during the expansion stroke. Based on the plot, the temperature reduction is reduced with the increased amount of injected water. The combustion temperature reduction will lead to lower exhaust temperature which reduces the turbine inlet temperature. The potential of reduced fuel consumption can be seen with the reduced need of fuel enrichment.

The NOx emission formation heavily relies on the peak temperature in the cylinder [14]. Even though the emission study was not conducted in this study, the lower combustion temperature implies that the WI can potentially lower the production of NOx emission.

\section{Effect of Port WI on The Engine Performance}

Figure 7(a) shows the engine torque curves while Figure 7(b) displays the IMEP comparison between various cases. As shown from the plots, the torque and IMEP increase when the amount of water injected is increased. The maximum torque gain is $10.8 \%$ when the engine is operating at $3000 \mathrm{rpm}$. The IMEP also improved by a maximum of $8.65 \%$ at $3000 \mathrm{rpm}$. The performance gain from the port WI is qualitatively comparable with the results by Iacobacci et al. [9] in which the best IMEP gain from their study is $7.3 \%$ with $20 \%$ injection of water to fuel mass ratio. The IMEP increased because the charge density going into the cylinder increased. Therefore, the torque is still increased despite the reduced combustion temperature.

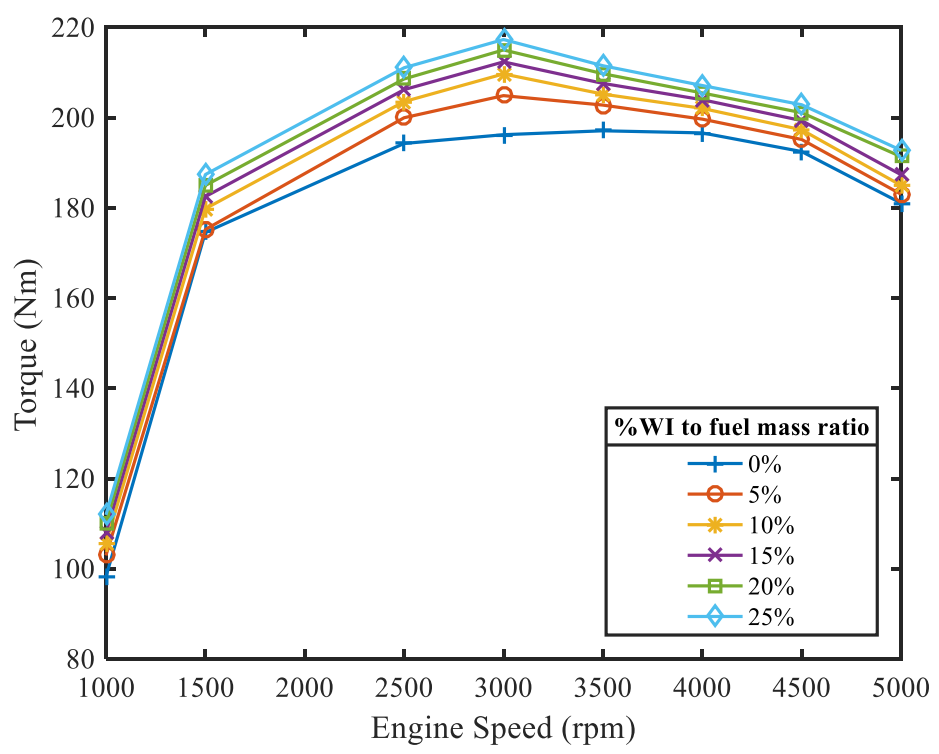

(a) 


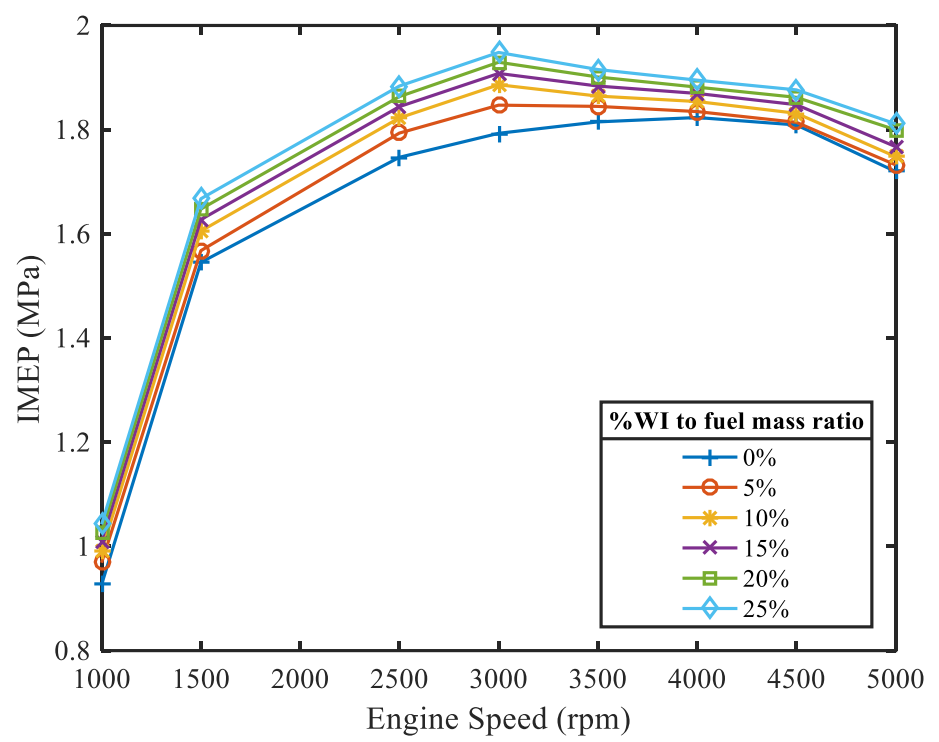

(b)

Figure 7. (a) IMEP and; (b) torque comparison responding to engine speed for various cases of WI percentage to fuel mass ratio.

\section{CONCLUSION}

The detailed port WI modelling via AVL BOOST had been extensively discussed in the paper. The port WI is applied on a 1.6-litre 4-cylinder SI turbocharged engine to evaluate its effect on engine performances. Port WI was chosen because it is the simplest and the most practical WI strategy. Port WI is also the only injection technique that is applied on to a production engine. Different ratio of injected water to fuel mass fraction was used in this study and the following conclusions were drawn:

i. The maximum gain of engine torque and IMEP is $10.8 \%$ and $8.65 \%$, respectively at $3000 \mathrm{rpm}$.

ii. The ability to control the combustion temperature indicates the ability to lower the exhaust temperature and turbine inlet temperature which reduce the usage of mixture enrichment. Hence, WI has the potential to reduce the fuel consumption.

iii. Lower combustion temperature creates the potential for lower NOx emission from the combustion.

iv. The in-cylinder pressure decreases toward the end of the compression stroke which implies that the compression work is reduced, improving the engine efficiency.

Although the WI simulation results produced by AVL BOOST is not yet validated with an experiment, the simulation results are comparable to other published data qualitatively and quantitatively. The simulation result in this paper could be experimentally verified in future work. However, the focus of this paper is to demonstrate the modelling of port WI via AVL BOOST. The simulation results are the proof that the model can predict the engine parameters accurately.

\section{ACKNOWLEDGEMENT}

The authors would like to thank Universiti Teknologi Malaysia for the financial support under GUP COE grant Q.J130000.2424.04G07. 


\section{REFERENCES}

[1] Brooke L. Bosch developing new water-injection system for production engines. SAE International; 2015.

[2] Bulander DR. Powertrain Optimization using a Comprehensive Systems Approach. In 36th Interational Vienna Motor Symposium 2015. Vienna: Bosch; 2015.

[3] Breda S, Berni F, d'Adamo A, Testa F, Severi E, Cantore G. Effects on Knock Intensity and Specific Fuel Consumption of Port Water/Methanol Injection in a Turbocharged GDI Engine: Comparative Analysis. Energy Procedia. 2015;82:96102.

[4] Bozza F, De Bellis V, Teodosio L. Potentials of cooled EGR and water injection for knock resistance and fuel consumption improvements of gasoline engines. Applied Energy. 2016;169:112-25.

[5] Rothrock AM, Krsek A, Jr, Jones AW. The induction of water to the inlet air as a means of internal cooling in aircraft engine cylinder. National Advisory Committee for Aeronautics. Langley Aeronautical Lab.; Langley Field, VA, United States1943. p. 17.

[6] Lanzafame R. Water Injection Effects In A Single-Cylinder CFR Engine. SAE International; 1999.

[7] Tornatore C, Siano D, Marchitto L, Iacobacci A, Valentino G, Bozza F. Water Injection: a Technology to Improve Performance and Emissions of Downsized Turbocharged Spark Ignited Engines. SAE International Journal of Engines. 2017;10:2319-29.

[8] Mingrui W, Thanh Sa N, Turkson RF, Jinping L, Guanlun G. Water injection for higher engine performance and lower emissions. Journal of the Energy Institute. 2017;90:285-99.

[9] Arturo Iacobacci LM, Gerardo Valentino Water Injection to Enhance Performance and Emissions of a Turbocharged Gasoline Engine under High Load Condition. SAE International Journal of Engines. 2017;10:928-37.

[10] Jeremy Worm, Jeffrey Naber, Joel Duncan, Sam Barros, Atkinson W. Water Injection as an Enabler for Increased Efficiency at High-Load in a Direct Injected, Boosted, SI Engine SAE International Journal of Engines. 2017;10:951-8.

[11] Worm J. The Impact of Water Injection on Spark Ignition Engine Performance under High Load Operation [Open Access Dissertation]: Michigan Technological University; 2017.

[12] Berni F, Breda S, Lugli M, Cantore G. A Numerical Investigation on the Potentials of Water Injection to Increase Knock Resistance and Reduce Fuel Consumption in Highly Downsized GDI Engines. Energy Procedia. 2015;81:826-35.

[13] Bozza F, De Bellis V, Giannattasio P, Teodosio L, Marchitto L. Extension and Validation of a 1D Model Applied to the Analysis of a Water Injected Turbocharged Spark Ignited Engine at High Loads and over a WLTP Driving Cycle. SAE Int J Engines. 2017;10:2141-53.

[14] Battistoni M, Grimaldi C, Cruccolini V, Discepoli G, De Cesare M. Assessment of Port Water Injection Strategies to Control Knock in a GDI Engine through Multi-Cycle CFD Simulations2017.

[15] Wei M, Nguyen T, Turkson R, Guo G, Liu J. The Effect of Water Injection on the Control of In-Cylinder Pressure and Enhanced Power Output in a Four-Stroke Spark-Ignition Engine. Sustainability. 2016;8:993. 
One-Dimensional Simulation Using Port Water Injection for a Spark Ignition Engine

[16] AVL. Advanced Simulation Technologies-Simulation Tools and Methods for Powertrain Development. AVL; 2016. 